\title{
Anti-proliferative and cytotoxic activity of rosuvastatin against melanoma cells
}

\author{
Malgorzata Maj ${ }^{1}$, Rafal Czajkowski², Barbara Zegarska³, Bogna Kowaliszyn ${ }^{4}$, Marta Pokrywczynska $^{5}$, Tomasz Drewa ${ }^{6,7}$ \\ ${ }^{1}$ Chair of Urology, Department of Tissue Engineering, Nicolaus Copernicus University, Bydgoszcz, Poland \\ ${ }^{2}$ Chair of Dermatology, Sexually Transmitted Diseases and Immunodermatology, Nicolaus Copernicus University, Bydgoszcz, Poland \\ ${ }^{3}$ Department of Cosmetology and Aesthetic Dermatology, Nicolaus Copernicus University, Bydgoszcz, Poland \\ ${ }^{4}$ Department of Genetics and General Animal Breeding, University of Science and Technology, Bydgoszcz, Poland \\ ${ }^{5}$ Chair of Urology, Department of Regenerative Medicine, Nicolaus Copernicus University, Bydgoszcz, Poland \\ ${ }^{6}$ Chair of Urology, Clinic of General and Oncological Urology, Nicolaus Copernicus University, Bydgoszcz, Poland \\ ${ }^{7}$ Department of Urology, Nicolaus Copernicus Hospital, Torun, Poland
}

Adv Dermatol Allergol 2016; XXXIII (4): 257-262 DOI: 10.5114/ada.2016.61601

\begin{abstract}
Introduction: Statins are considered potential candidate agents for melanoma chemoprevention. Statin-induced mevalonate pathway inhibition leads to reduction of cholesterol synthesis and also to decreased cellular levels of non-steroidal isoprenoids, geranylgeranyl pyrophosphate and farnesyl pyrophosphate. This results in the impairment of protein prenylation which affects carcinogenesis.

Aim: To analyze anti-proliferative and cytotoxic activity of rosuvastatin against melanoma cells.

Material and methods: Melanoma cell lines (A375 and WM1552C) and normal fibroblasts (BJ) were used as the primary research material. Cells were treated with rosuvastatin at concentrations ranging from $0.01 \mu \mathrm{M}$ to $10 \mu \mathrm{M}$. Cell viability was analyzed with the use of an MTT assay. Expression of proliferation marker Ki67 was assessed on the basis of immunofluorescence staining.

Results: Rosuvastatin reduced A375 and BJ cell viability in a time- and dose-dependent manner. After $72 \mathrm{~h}$ incubation, the $\mathrm{IC}_{50}$, half maximal inhibitory concentration, was $2.3 \mu \mathrm{M}$ for melanoma cells and $7.4 \mu \mathrm{M}$ for normal fibroblasts. In turn, rosuvastatin exhibited relatively lower activity against WM1552C cells. A significant reduction of Ki67 expression was also noted for BJ fibroblasts after prolonged incubation with the tested drug.

Conclusions: The results indicate that the anti-melanoma properties of rosuvastatin are highly dependent on the tumor cell line assessed. However, the concentrations required to decrease melanoma cell viability in vitro exceed the plasma concentrations reached in patients treated with rosuvastatin at well-tolerated doses. What is more disturbing, reduction of proliferation and viability observed in BJ fibroblasts indicated that rosuvastatin at high doses may be toxic for normal cells.
\end{abstract}

Key words: rosuvastatin, melanoma, chemoprevention.

\section{Introduction}

Melanoma remains the leading cause of deaths from skin cancer. For this reason, growing attention has recently been paid to the inhibition of carcinogenesis at all three stages, initiation, promotion and progression, with the use of synthetic or naturally occurring chemical compounds, which is collectively termed chemoprevention [1, 2]. Given their widespread availability and documented long-term safe use, particular attention has been drawn to statins that act through the inhibition of the mevalonate pathway. Reduced levels of non-steroidal intermediate products of the cholesterol synthesis pathway, e.g. farnesyl pyrophosphate and geranylgeranyl pyrophosphate, impairs prenylation of various signaling proteins involved in the regulation of cell proliferation, differentiation and apoptosis which may modulate cancer cells biology [3-5].

Several reports have indicated that statins possess anticancer properties under in vitro conditions. Time- and

Address for correspondence: Malgorzata Maj PhD, Department of Tissue Engineering, Ludwik Rydygier Collegium Medicum, Nicolaus Copernicus University, 24 Karlowicza St, 85-092 Bydgoszcz, Poland, phone: +48 5258538 23, e-mail: m_maj@onet.pl Received: 21.10.2015, accepted: 25.10.2015. 
dose-dependent viability reduction has been observed in a number of cancer cells treated with different statins. In human melanoma cell lines, lovastatin has been shown to reduce viability/proliferation and induce caspase-dependent apoptosis through a geranylation-specific mechanism [6]. Similar results have been obtained using simvastatin. Viability reduction, DNA fragmentation, cell cycle arrest and subsequent increase in the mRNA levels of p21 and p27 have been observed after prolonged incubation with the tested drug. However, the level of sensitivity to simvastatin is different in various cell lines used in this study [7]. In turn, atorvastatin has been reported to inhibit rho geranyl-geranylation and thus reduce the metastatic potential of human melanoma cells in vitro [8].

To our knowledge, rosuvastatin activity against melanoma cells has not been assessed to date. Its anti-proliferative and cytotoxic activity has been demonstrated in the case of thyroid cancer cells in vitro. Rosuvastatin treatment caused an increase in caspase-3 activity and apoptosis confirmed by DNA fragmentation analysis [9]. Viability reduction has also been noted in hepatic, breast and cervical cancer cell lines [10]. Rosuvastatin has also been reported to reduce the cellular proliferation, colony formation and invasive potential of prostate cancer cells [11].

\section{Aim}

A growing body of literature reports indicates that statins may possess chemopreventive activity against melanoma cells through pleiotropic activity. Rosuvastatin is the only drug of this group that has not had its activity against melanoma cells assessed to date. For this reason, the analysis of anti-proliferative and cytotoxic activity of rosuvastatin under in vitro conditions was the aim of this work.

\section{Material and methods}

\section{Cell culture}

Human melanoma cell lines (A375 and WM1552C) and normal fibroblasts (BJ) were obtained from the American Type Culture Collection. Cells were routinely cultured in DMEM/Ham's F-12 supplemented with $10 \%$ fetal bovine serum, $5 \mu \mathrm{g} / \mathrm{ml}$ amphotericin B, $100 \mathrm{U} / \mathrm{ml}$ penicillin, and $100 \mu \mathrm{g} / \mathrm{ml}$ streptomycin (Sigma-Aldrich, Germany). Cells were cultured at $37^{\circ} \mathrm{C}$ in a humidified atmosphere containing $5 \% \mathrm{CO}_{2}$.

\section{Viability measurement}

Cells were seeded on 24-well plates (BD Biosciences, USA) at a density of $1 \times 10^{4}$ per well for A375 cell line, $3 \times$ $10^{4}$ for BJ cell line, and $5 \times 10^{4}$ for WM1552C cell line. Differences in cell seeding density were due to the different growth characteristics of cultured cells that, at the time of use for a test, should be in a logarithmic growth phase. After $48 \mathrm{~h}$ of preincubation, cells were treated for $72 \mathrm{~h}$ with rosuvastatin at concentrations ranging from $0.01 \mu \mathrm{M}$ to $10 \mu \mathrm{M}$. Cell viability was assessed with a tetrazolium-based colorimetric MTT assay. After $2 \mathrm{~h}$ of incubation with MTT solution $(500 \mu \mathrm{g} / \mathrm{ml}$, SigmaAldrich, Germany), formazan crystals were dissolved in dimethyl sulfoxide (POCH, Poland) and absorbance was measured at $570 \mathrm{~nm}$ using a UV-VIS spectrophotometer (Varian CARY 1E UV-Vis, Agilent Technologies, USA). Cell viability was expressed as a percentage of the untreated control.

\section{Proliferation analysis}

Cells were seeded on $12 \mathrm{~mm}$ diameter coverslips (WITKO, Poland) at $5 \times 10^{3}$ for A375 cell line, $15 \times 10^{3}$ for BJ cell line and $25 \times 10^{3}$ for WM1552C cell line. After $48 \mathrm{~h}$ of preincubation, cells were treated with rosuvastatin at concentrations ranging from $0.1 \mu \mathrm{M}$ to $5 \mu \mathrm{M}$ for $72 \mathrm{~h}$. Cell proliferation was measured on the basis of Ki67 expression. Cells seeded on coverslips were washed with PBS (Sigma-Aldrich, Germany) and fixed in 2\% formaldehyde (Sigma-Aldrich, Germany). Before permeabilization with 0.1\% Triton X-100 (Sigma-Aldrich, Germany), non-specific binding sites were blocked with 2\% BSA (Sigma-Aldrich, Germany). Cells were then incubated with primary rabbit antibody against Ki67 (dilution 1 : 100, 1.5 h, RT) (Novusbio, USA). After washing with Triton X-100 and a second incubation with BSA, cells were incubated with goat antirabbit FITC conjugated secondary antibody (dilution 1 : 1500, 1 h, RT) (Sigma-Aldrich, Germany). Before counterstaining with DAPI $(0.1 \mu \mathrm{g} / \mathrm{ml})$ (Sigma-Aldrich, Germany), coverslips were washed in PBS and finally mounted in Aqua-Poly/Mount (Polysciences, USA). Ki67 expression was analyzed using NIS-Elements 4.0 software in an Eclipse E800 fluorescence microscope (Nikon, Japan). The number of stained cells per $10 \times$ microscope field was counted. Cell proliferation was expressed as a percentage of the untreated control.

\section{Statistical analysis}

Experiments were performed in triplicate. All data were presented as means \pm SD. The means were compared using one-way ANOVA, followed by Tukey's posthoc test using Graph Pad Prism 6.0 (Demo Version). Values of $p$ lower than 0.05 were considered statistically significant.

\section{Results}

\section{Cells viability assessed on the basis of MTT assay}

Rosuvastatin reduced the viability of A375 melanoma cells and BJ fibroblasts in a dose-dependent manner (Figure 1). After $72 \mathrm{~h}$ treatment with rosuvastatin at a concentration of $5 \mu \mathrm{M}$, the metabolic activity of A375 cancer cells was reduced by $79.2 \%$ and the calculated half maxi- 

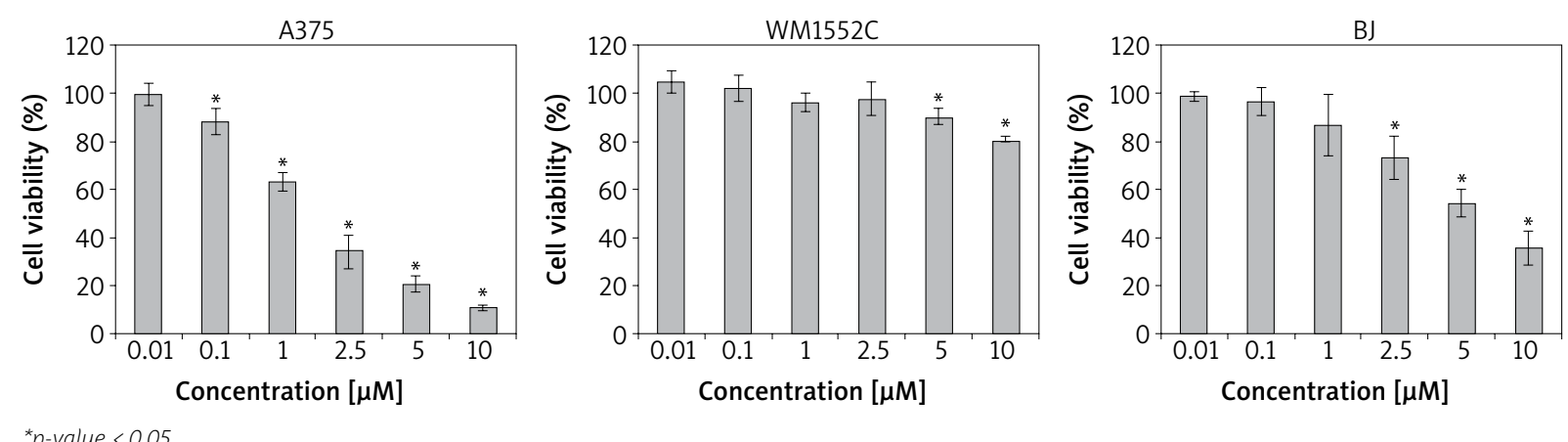

Figure 1. Cells viability after $72 \mathrm{~h}$ treatment with rosuvastatin assessed on the basis of MTT assay

mal inhibitory concentration $\left(\mathrm{IC}_{50}\right)$ was $2.3 \mu \mathrm{M}$ (Table 1). Rosuvastatin-treated cells were rounded and detached from the growth surface (Figure 2). In turn, WM1552C melanoma cells were insensitive to rosuvastatin at concentrations ranging from $0.01 \mu \mathrm{M}$ to $2.5 \mu \mathrm{M}$. Slightly reduced metabolic activity was observed when cancer cells were incubated with the tested drug at a concentration of $5 \mu \mathrm{M}$ (Figure 1). Rosuvastatin significantly reduced the viability of normal BJ fibroblasts. At a concentration of $5 \mu \mathrm{M}$, cells displayed a more than $60 \%$ decrease in viability. Calculated IC 50 was $7.4 \mu \mathrm{M}$ (Table 1). After treatment with increasing concentrations of rosuvastatin, fibroblasts became shrunken and partly lost their adherent phenotype (Figure 2).

\section{Cell proliferation assessed on the basis of Ki67 expression}

Incubation with rosuvastatin reduced the expression of Ki67 proliferation markers in both melanoma cell lines, but only at a concentration of $5 \mu \mathrm{M}$. After $72 \mathrm{~h}$ treatment, Ki67 expression in A375 cells was reduced by $29.6 \%$ in comparison to the control. In the same conditions, the number of Ki67-positive WM1552C cells was reduced by 14.2\% (Figure 3 A). In turn, a significant and dose-dependent reduction of Ki67 expression was observed in normal BJ fibroblasts (Figure 3 B). At a concentration of 0.1 $\mu M$, the number of positive cells was reduced by $20.1 \%$, and at $5 \mu \mathrm{M}$ more than $88.2 \%$ of cells were Ki67-negative (Figure $3 \mathrm{~A}$ ).

\section{Discussion}

In recent years, growing interest has been focused on cancer chemoprevention that is defined as the use of natural or synthetic compounds to prevent, inhibit or reverse the multi-step process of carcinogenesis and its secondary prevention (early diagnosis of skin melanoma) $[12,13]$. The use of statins as melanoma chemopreventive agents has been based on epidemiological data suggesting their effect on melanoma incidence [14]. Numerous reports from preclinical studies have confirmed the cytotoxic and anti-proliferative effects of statins on
Table 1. Half maximal inhibitory concentration $\left(\mathrm{IC}_{50}\right)$ values for rosuvastatin $( \pm S D)$

\begin{tabular}{lc}
\hline Cell line & $\mathrm{IC}_{50}[\mu \mathrm{M}]$ \\
\hline A375 & $2.3 \pm 0.3$ \\
\hline WM1552C & $43.9 \pm 2.8$ \\
\hline BJ & $7.4 \pm 0.7$ \\
\hline
\end{tabular}

melanoma cell lines $[6,7,15]$ and animal models $[16,17]$. Meta-analysis of clinical trials has not, however, been able to demonstrate any correlation between statin use and melanoma incidence [18-20]. The most recent literature report showed that, instead of preventing melanoma incidence, statins at well-tolerated doses might reduce the growth and metastatic spread of melanoma cells and improve survival [21].

Inhibition of the mevalonate pathway depresses the synthesis of non-steroidal isoprenoids that, through posttranslational modification, activate e.g. small $G$ proteins involved in various cellular processes such as proliferation, differentiation and apoptosis. Thus, by influencing protein prenylation statins may alter the biology of cancer cells [22]. Studies on melanoma cell lines by Shellmann et al. demonstrated that the inhibition of protein prenylation mediated by geranylgeranyl pyrophosphate reduces cell viability and induces apoptosis via a geranylation specific mechanism. After $72 \mathrm{~h}$ treatment with lovastatin at a concentration of $4 \mu \mathrm{M}$, cell viability was reduced by $30 \%$ to $80 \%$, depending on the melanoma cell line. Similar to our observations, lovastatin-treated cells were rounded in shape and detached from the growth surface [6].

The varying sensitivity of melanoma cell lines to simvastatin was demonstrated by Saito et al. Simvastatin showed anti-proliferative activity against melanoma cells through induction of apoptosis and cell cycle arrest. Time- and dose-dependent cytotoxicity was also observed in normal human fibroblasts, which is consistent with our results. The addition of geranylgeranyl pyrophosphate to the culture medium completely reversed simvastatin-induced inhibition of cell growth, indicating 

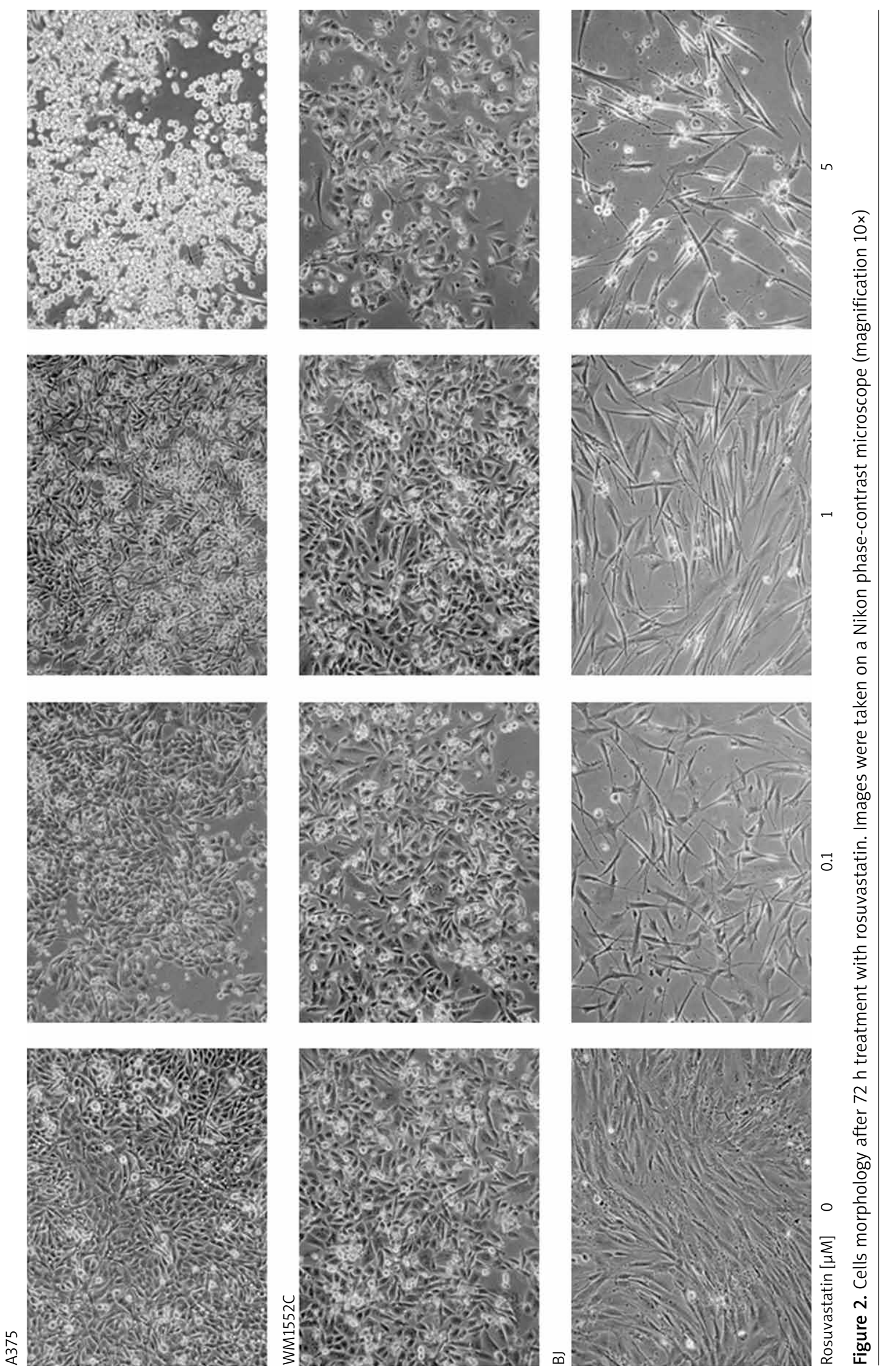
A

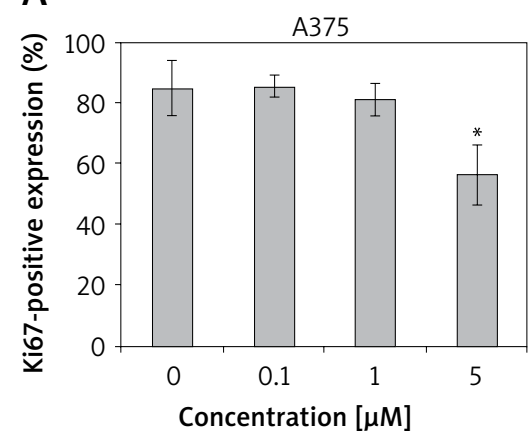

B
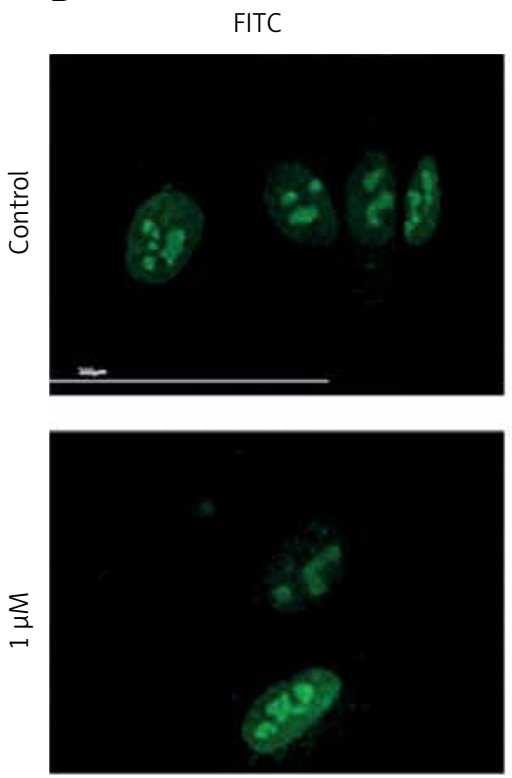

WM1552C

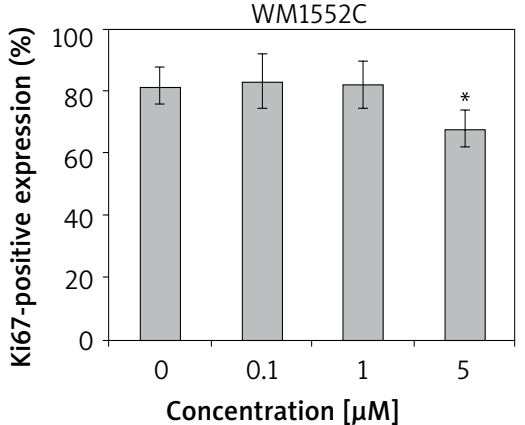

DAPI
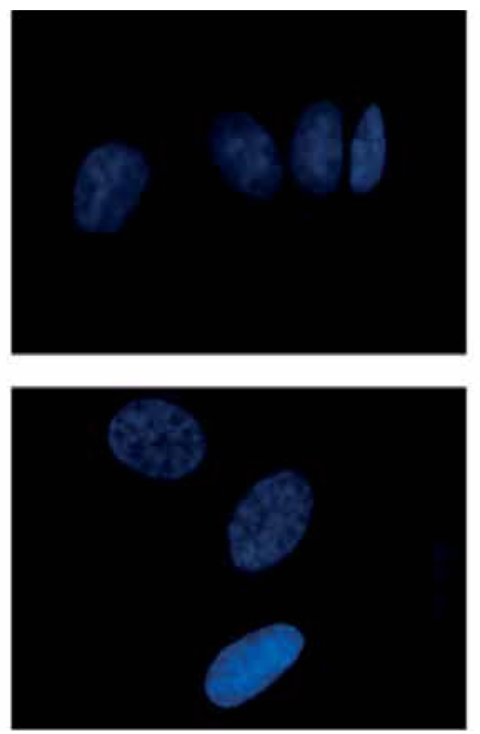

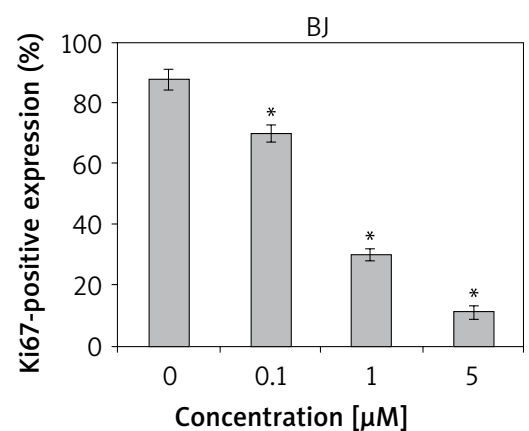

Concentration $[\mu \mathrm{M}]$

MERGED
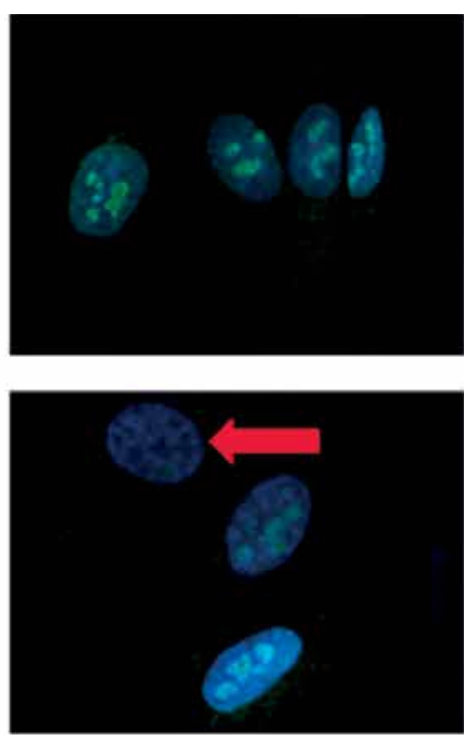

${ }^{*} p$-value $<0.05$.

Figure 3. Cells proliferation after $72 \mathrm{~h}$ treatment with rosuvastatin assessed on the basis of Ki67 expression. A - Proliferation expressed as a percentage of the untreated control. B - BJ cells stained for Ki67. Images were taken on a Nikon fluorescence microscope (magnification 100×). Arrow indicates Ki67-negative cell. Scale bar, $200 \mu \mathrm{m}$

that protein prenylation is implicated in the decrease in cell viability [7]. The inhibitory effects of statins on melanoma cell proliferation and viability have been confirmed by other research groups [14, 23, 24].

Studies on a murine B16F10 melanoma cell line confirmed the cytotoxic activity of statins in vitro [25]. However, in an animal model fluvastatins failed to reduce tumor growth [26]. In turn, atrovastatin and fluvastatin significantly inhibited lung metastasis. The observed inhibitory effect was due to reduced expression of matrix metalloproteinases, integrin $\alpha 2$, integrin $\alpha 4$, integrin $\alpha 5$ and reduced adhesion to extracellular matrix proteins, i.e. type I collagen, type IV collagen, fibronectin, and laminin [15]. These results indicate a prophylactic potential of statins against metastasis that should be further explored.

\section{Conclusions}

The results of our study showed significant differences in the sensitivity of melanoma cell lines to rosuvastatin. What is more concerning, rosuvastatin used at the same concentration range exhibited cytotoxic and anti-proliferative activity against normal human fibroblasts. Investigation of both mechanisms involved in the anti-proliferative and anti-metastatic activity of rosuvastatin and whether these effects are reversible with the addition of geranylgeranyl pyrophosphate is necessary to evaluate the anti-melanoma activity of rosuvastatin.

\section{Acknowledgments}

The study was funded by a grant for young scientists (MN-2/WL) from the Faculty of Medicine, Nicolaus Copernicus University, Ludwik Rydygier Collegium Medicum. 


\section{Conflict of interest}

The authors declare no conflict of interest.

\section{References}

1. Nikolaou V, Stratigos AJ. Emerging trends in the epidemiology of melanoma. Br J Dermatol 2014; 170: 11-9.

2. Czajkowski R, Męcińska-Jundziłł K. Current aspects of vitiligo genetics. Postep Derm Alergol 2014; 31: 247-55.

3. Garcia-Ruiz C, Morales A, Fernandez-Checa JC. Statins and protein prenylation in cancer cell biology and therapy. Anticancer Agents Med Chem 2012; 12: 303-15.

4. Osmak M. Statins and cancer. Current and future prospects. Cancer Lett 2012; 324: 1-12.

5. Altwairgi AK. Statins are potential anticancerous agents. Oncol Rep 2015; 33: 1019-39.

6. Shellman YG, Ribble D, Miller L, et al. Lovastatin-induced apoptosis in human melanoma cell lines. Melanoma Res 2005; 15: 83-9.

7. Saito A, Saito N, Mol W, et al. Simvastatin inhibits growth via apoptosis and the induction of cell cycle arrest in human melanoma cells. Melanoma Res 2008; 18: 85-94.

8. Collisson EA, Kleer C, Wu M, et al. Atorvastatin prevents RhoC isoprenylation, invasion, and metastasis in human melanoma cells. Mol Cancer Ther 2003; 2: 941-8.

9. Zeybek ND, Gulcelik NE, Kaymaz FF, et al. Rosuvastatin induces apoptosis in cultured human papillary thyroid cancer cells. J Endocrinol 2011; 210: 105-15.

10. El Sharkawi FZ, El Shemy HA, Khaled HM. Possible anticancer activity of rosuvastatine, doxazosin, repaglinide and oxcarbazepin. Asian Pac J Cancer Prev 2014; 15: 199-203.

11. Brown M, Hart C, Tawadros T, et al. The differential effects of statins on the metastatic behaviour of prostate cancer. $\mathrm{Br}$ J Cancer 2012; 106: 1689-96.

12. Steward WP, Brown K. Cancer chemoprevention: a rapidly evolving field. Br J Cancer 2013; 109: 1-7.

13. Emiroglu N, Cengiz FP, Hofmann-Wellenhof R. Dermoscopic and clinical features of trunk melanomas. Postep Dermatol Alergol 2014; 31: 362-7.

14. Downs JR, Clearfield M, Weis S, et al. Primary prevention of acute coronary events with lovastatin in men and women with average cholesterol levels: results of AFCAPS/TexCAPS. Air Force/Texas Coronary Atherosclerosis Prevention Study. JAMA 1998; 279: 1615-22.

15. Glynn SA, O'Sullivan D, Eustace AJ, et al. The 3-hydroxy3-methylglutaryl-coenzyme A reductase inhibitors, simvastatin, lovastatin and mevastatin inhibit proliferation and invasion of melanoma cells. BMC Cancer 2008; 8: 9.

16. Kidera Y, Tsubaki M, Yamazoe Y, et al. Reduction of lung metastasis, cell invasion, and adhesion in mouse melanoma by statin-induced blockade of the Rho/Rho-associated coiledcoil-containing protein kinase pathway. J Exp Clin Cancer Res 2010; 29: 127.

17. Pich C, Teiti I, Rochaix P, et al. Statins reduce melanoma development and metastasis through MICA overexpression. Front Immunol 2013; 4: 62.

18. Dale KM, Coleman Cl, Henyan NN, et al. Statins and cancer risk: a meta-analysis. JAMA 2006; 295: 74-80.

19. Bonovas S, Nikolopoulos G, Filioussi K, et al. Can statin therapy reduce the risk of melanoma? A meta-analysis of randomized controlled trials. Eur J Epidemiol 2010; 25: 29-35.

20. Li X, Wu XB, Chen Q. Statin use is not associated with reduced risk of skin cancer: a meta-analysis. Br J Cancer 2014: 110: 802-7.
21. Livingstone E, Hollestein LM, van Herk-Sukel MP, et al. Statin use and its effect on all-cause mortality of melanoma patients: a population-based Dutch cohort study. Cancer Med 2014; 3: 1284-93.

22. Vallianou NG, Kostantinou A, Kougias M, Kazazis C. Statins and cancer. Anticancer Agents Med Chem 2014; 14: 706-72.

23. Depasquale I, Wheatley DN. Action of Lovastatin (Mevinolin) on an in vitro model of angiogenesis and its co-culture with malignant melanoma cell lines. Cancer Cell Int 2006; 6: 9.

24. Minichsdorfer C, Hohenegger M. Autocrine amplification loop in statin-induced apoptosis of human melanoma cells. Br J Pharmacol 2009; 157: 1278-90.

25. Feleszko W, Mlynarczuk I, Nowis D. In vitro antitumor activity of cerivastatin, a novel and potent HMG-CoA reductase inhibitor. FEBS Lett 2001; 503: 219-20.

26. Klement $\mathrm{H}$, Rak J. A disconnect between antitumor and antiangiogenic effects of fluvastatin in vitro and in vivo. Neoplasma 2006; 53: 111-8. 